\title{
Concepções de gênero dos/as estudantes no Curso Normal de Nível Médio
}

\author{
Gender conceptions of students in the Normal Middle Level Course \\ Concepciones de género de los alumnos del Curso Normal Nivel Medio
}

Marcieli Luísa Zimmer ${ }^{1}$; Rúbia Emmel2; Luana Gabriele Spengler Fischer ${ }^{3}$; Gustavo Felipe Bastian ${ }^{4}$

\section{RESUMO}

Este relato tem como temática as relações de gênero na formação inicial de professores/as. Teve como objetivo compreender as concepções dos estudantes do Curso Normal sobre gênero, com o intuito de desconstruir os estereótipos sociais instituídos. Esta pesquisa em educação, de abordagem qualitativa, foi realizada através de uma pesquisa-ação. Primeiramente desenvolveu-se uma pesquisa bibliográfica com autores da área, em seguida foi realizada a aplicação de um questionário a 27 estudantes de uma escola estadual de Santa Rosa/RS. As análises dos resultados foram realizadas por meio de categorias definidas a priori, que são: concepção de gênero; importância do estudo das temáticas; participação em atividades referentes à sexualidade e gênero. Ao final das atividades propostas nesta intervenção, percebeu-se que muitos estudantes mudaram suas concepções, adquirindo e desenvolvendo conhecimentos acerca da temática. A partir disso, é possível compreender que é importante trabalhar, com os alunos, assuntos que ainda hoje são considerados tabus, e fazer isso por meio de uma perspectiva dialógica é primordial, uma vez que a escola tem o papel de formar cidadãos críticos e reflexivos, de formar para a cidadania.

Palavras-chave: Estereótipos; Ensino de Ciências; Formação Inicial de Professores; Gênero.

\begin{abstract}
This report is about gender in the initial training of teachers. It aimed to understand the conceptions of the students of the Normal Course on gender, deconstructing social stereotypes. This qualitative approach to education research was carried out through an action research, first with a research with authors in the field then the application of a questionnaire to students. The analyzes of the results were carried out through categories defined a priori: conception of gender; importance of studying the themes; participation in activities related to sexuality and gender. At the end of the activities proposed in this intervention, it is clear that many made the reflection and changed their responses. Therefore, it is important to work with students talking about
\end{abstract}

\footnotetext{
${ }^{1}$ Formada no Curso Normal com habilitação em docência na Educação Infantil e Anos Iniciais do Ensino Fundamental e Acadêmica do Curso de Licenciatura em Ciências Biológicas no Instituto Federal Farroupilha (IFFAR), Campus Santa Rosa, Santa Rosa/RS - Brasil. E-mail: marcielizimmer5@gmail.com

${ }^{2}$ Licenciada em Pedagogia, Mestre em Educação e Doutora em Educação Nas Ciências. Professora do Instituto Federal Farroupilha (IFFAR), Câmpus Santa Rosa, Santa Rosa/RS - Brasil. E-mail: rubia.emmel@iffarroupilha.edu.br

${ }^{3}$ Formada no Curso Normal com habilitação em docência na Educação Infantil e Anos Iniciais do Ensino Fundamental e acadêmica do Curso de Licenciatura em Ciências Biológicas no Instituto Federal Farroupilha (IFFAR), Câmpus Santa Rosa, Santa Rosa/RS - Brasil. E-mail: luanags8@hotmail.com

${ }^{4}$ Acadêmico do Curso de Licenciatura em Ciências Biológicas no Instituto Federal Farroupilha (IFFAR), Câmpus Santa Rosa, Santa Rosa/RS - Brasil. E-mail: gustavofelipebastian@gmail.com
} 
subjects that are still considered taboo today, since the school has the role of forming a critical and reflective citizen, training for citizenship.

Keywords: Stereotypes; Science teaching; Initial Teacher Training; Genre.

\section{RESUMEN}

Este informe trata sobre el género en la formación inicial del profesorado. Tuvo como objetivo comprender las concepciones de los alumnos del Curso Normal sobre género, deconstruyendo los estereotipos sociales. Este abordaje cualitativo de la investigación en educación se realizó a través de una investigación acción, primero con una investigación con autores en el campo, seguido de la aplicación de un cuestionario a los estudiantes. El análisis de los resultados se realizó a través de categorías definidas a priori: concepción de género; importancia de estudiar los temas; participación en actividades relacionadas con la sexualidad y el género. Al final de las actividades propuestas en esta intervención, queda claro que muchos hicieron la reflexión y cambiaron sus respuestas. Por eso, es importante trabajar con los alumnos hablando de temas que todavía hoy se consideran tabú, porque la escuela tiene el rol de formar un ciudadano crítico y reflexivo, formador para la ciudadanía.

Palabras clave: Estereotipos; Enseñanza de las ciencias; Formación inicial del profesorado; Genero.

\section{INTRODUÇÃO}

Este trabalho relata uma pesquisa-ação que foi desenvolvida no contexto da formação inicial de professores/as: no Curso Normal do Ensino Médio. A temática abordada, das relações de gênero, tem grande importância para o desenvolvimento da integralidade dos/as estudantes como cidadãos e sujeitos ativos dos processos de aprendizagem (BUGALSKI; URBAN, 2016). Embora entendamos que se trata de um tema conflitante e que as problemáticas se expressam de modos diferentes a todos/as, inclusive entre crianças nos seus primeiros anos de vida, sobressai o papel humanizador que a educação possui na constituição de sujeitos que compreendam as discussões de gênero. Não obstante, é um objeto que pode ser discutido criticamente na formação de professores dos Anos Iniciais ou Educação Infantil, uma vez que pode ser abordado por meio do ensino de Ciências na Educação Básica a partir de um viés crítico e problematizador.

Consideramos que no desenvolvimento infantil a informação interfere na formação da personalidade dos indivíduos (VYGOTSKY, 1978). Desse modo, o/a professor/a pode assumir um papel de guia e ensinar o/a estudante a interpretar as informações que recebe, posto que, muitas vezes, as dúvidas que não explicadas em casa são trazidas para as aulas, e o/a docente acaba tornando-se o responsável que deve explicar e elucidar tais assuntos.

Assim, as questões relacionadas a gênero e sexualidade são amplamente discutidas na sociedade atual e causam polêmicas em diversos segmentos, o que gera comportamentos equivocados dos indivíduos. Por isso, os/as estudantes do Curso Normal de nível Médio, como futuros/as professores/as, devem estar preparados/as para desenvolver temas como esses, os quais podem ser integrados ao ensino de Ciências por meio de uma abordagem mais holística e menos fragmentada de conhecimento (MACEDO, 2005). Consideramos que, segundo Macedo (2005), assim como em outros temas estudados nas ciências, a sexualidade é "des-historicizada" e "desculturalizada".

A docência e a sua formação compõem grande parte da educação e a Lei de Diretrizes e Bases da Educação Nacional (LDBEN) n. 9.394 (BRASIL, 1996), em seu Artigo 10, estabelece a abrangência da educação como: [...] "processos formativos que se desenvolvem na vida familiar, na convivência humana, no trabalho, nas instituições de ensino e pesquisa, nos movimentos sociais e organizações 
da sociedade civil e nas manifestações culturais" (BRASIL, 1996). Tendo isso em vista, esta pesquisa teve como objetivo compreender as concepções dos/as estudantes do Curso Normal acerca da temática das relações de gênero, com o intuito de desconstruir estereótipos sociais e culturais instituídos ou não por esses sujeitos. Assim, foi possível, por meio desta pesquisa-ação, perceber que influências possuem os discursos instituídos, assim como sanar dúvidas dos/as estudantes acerca do assunto em estudo. Tal atividade, por sua vez, os/as possibilitou reconhecer e problematizar os discursos de gênero, de modo a analisar suas concepções, e compreender a importância de desconstruir estereótipos disseminados na Educação Básica.

Acreditamos que as aprendizagens das crianças são influenciadas por diferentes instituições sociais, tais como mídia, família, igreja, escola etc. Em geral, as memórias que temos da escola contemplam tanto aspectos positivos como negativos (ROGERS, 2001; ALARCÃO, 2010). Destarte, a instituição escolar evoca memórias sobre a construção de amizades, descobertas, aprendizagens, alegrias, e, por outro lado, experiências negativas, resultadas por preconceitos e exclusão.

Diante disso, de acordo com Alarcão (2010), é possível compreender que a formação inicial de professores pode contribuir para a formação de profissionais mais reflexivos/as, que problematizem os acontecimentos escolares e auxiliem na formação de cidadãos humanizados. Nesse contexto, realizamos esta pesquisa-ação em uma escola de formação docente, atividade a partir da qual os/as estudantes apresentaram suas concepções sobre as temáticas, bem como dialogaram e construíram novos conhecimentos sobre as relações de gênero (CRUZ, 2011).

\section{METODOLOGIA}

Este estudo, de abordagem qualitativa, foi realizado a partir dos pressupostos da pesquisa-ação (FRANCO, 2005) e pelo mergulho crítico na práxis, por meio dos quais é possível perceber as expectativas, o oculto, que norteiam as reflexões sobre as práticas. Dessa forma, identificamos que as temáticas são pouco abordadas nas escolas e para um Curso de Formação Inicial de Professores/as é essencial intervir com reflexões sobre gênero e sexualidade.

Seguindo os pressupostos da pesquisa-ação, realizamos uma intervenção, no mês de outubro de 2019, na turma do 30 ano do Curso Normal (Ensino Médio) do Instituto Estadual de Educação Visconde de Cairu, localizado em Santa Rosa/RS. Essa instituição foi escolhida por ser a única do município a oferecer o Curso Normal. Durante a ação, que ocorreu com 27 estudantes, foi realizada a apresentação da temática gênero e os/as alunos responderam a um questionário no início e no final da aula. Essa dinâmica de responderem duas vezes ao instrumento foi instituída para que os alunos pudessem acrescentar respostas após a intervenção, já que, assim, poderíamos perceber se os/as estudantes mudaram ou não suas percepções sobre as temáticas estudadas.

Para a realização desta pesquisa-ação foram considerados os preceitos éticos e de direito previstos na Resolução 510/2016 do Conselho Nacional de Saúde (2016), a qual regulamenta a pesquisa com seres humanos. Deste modo, todos/as os/as participantes concordaram de forma livre, consentida e esclarecida a participar da investigação, assim como foram orientados acerca dos objetivos, dos procedimentos, do sigilo e do anonimato, e acerca do direito de participar ou não da pesquisa. A partir disso, visando garantir a autoria e o sigilo, os/as estudantes foram nomeados como: "E1, ..., E27". 
No primeiro momento, os/as estudantes responderam ao questionário com as seguintes perguntas abertas: 1) O que é gênero?; 2) Existe diferença entre gênero e sexualidade?; 3) Você sabe o que é estereótipo de gênero?; 4) Quais os estereótipos que você conhece?; 5) Você acredita que as temáticas "corpo, gênero e sexualidade" são importantes para serem discutidas na sua escola de formação? Por quê?; 6) Já participou de algum grupo de estudos, palestra, oficina, sobre o tema de sexualidade e gênero? Por meio deste instrumento de coleta de dados, criado para identificar os conhecimentos dos/as estudantes, foi possível conhecer a percepção inicial dos/as estudantes acerca da temática.

Em seguida foi realizada a explicação e a problematização do assunto, ação que ocorreu com o apoio de slides, imagens, vídeos e diálogos. Por último os/as estudantes completaram o seu questionário com outra cor de caneta (tabelado em cor vermelha), para anotar o que cada um compreendeu e refletiu após a ação, o que permitiu compreender a percepção final referente ao tema desenvolvido.

Ademais, é importante salientar que analisar as respostas dos/as estudantes permitiu refletir sobre suas concepções, sobre o planejamento e sobre as ações desenvolvidas neste processo de pesquisaação. Por isso, foi possível perceber as influências de nossa ação por meio dos conhecimentos das temáticas, que envolveram reflexão, explicação, dinâmicas, questionário e introspecção.

As respostas dos/as estudantes foram tabuladas e a análise temática dos discursos foi realizada. Lüdke e André (1986, p. 43) escrevem que "não existem normas fixas nem procedimentos padronizados para a criação de categorias, mas acredita-se que um quadro teórico consistente pode auxiliar uma seleção inicial mais segura e relevante". Assim, a análise temática de conteúdo (LÜDKE; ANDRÉ, 1986) foi realizada por meio de categorias temáticas definidas a priori, que são: concepção de gênero; concepção de estereótipo; importância do estudo das temáticas; participação em atividades referentes à sexualidade e gênero.

\section{REFERENCIAL TEÓRICO: REVISANDO AS CONCEPÇÕES DE GÊNERO E A FORMAÇÃO INICIAL DE PROFESSORES}

A formação inicial de professores/as pode contribuir para formação de docentes mais reflexivos, como propõe Alarcão (2010). A partir dos pressupostos dessa autora, consideramos que o diálogo, a observação, o planejamento, a ação e a reflexão das ações como caminhos possíveis para desenvolver uma pesquisa-ação que de fato ressignifique e desconstrua os preconceitos e/ou estereótipos que envolvem a discussão acerca das relações de gênero e seus atravessamentos no contexto escolar da Educação Básica.

As crianças são seres histórico-culturais e são influenciadas pelo seu meio. Segundo Vygotsky (1978, p. 46), "[...] o conhecimento do mundo pela criança, passa necessariamente pelo outro, adquirindo então a educação um papel fundamental". A partir dessa afirmação, é possível compreender o papel central que possui a linguagem para a constituição humana. Para Vygotsky (2003), a linguagem é um ato social construído socialmente e que surge nos grupos para que os seres humanos possam se comunicar. Entendemos que é pela linguagem, verbal ou não verbal, que nos constituímos. Ou seja, os discursos que ocorrem na linguagem podem ser desconstruídos ou reconstruídos por meio dos diálogos com os outros, por isso a relevância da intervenção aqui proposta.

O conceito de gênero pode ser definido como aquilo que identifica ou diferencia homens e mulheres (COLLING, 2019; TEDESCHI, 2019). No entanto, a partir de algumas compreensões das ciências 
sociais e da psicologia, principalmente, o gênero é entendido como aquilo que diferencia socialmente as pessoas, considerando os padrões histórico-culturais (LOURO, 1997). Por ser uma categoria social, o gênero pode ser construído e desconstruído, ou seja, pode ser entendido como algo mutável e não limitado.

Segundo Goellner (2010),

Por gênero entende-se a condição social por meio da qual nos identificamos como masculinos e femininos. É diferente de sexo, termo usado para identificar as características anatômicas que diferenciam os homens das mulheres e vice-versa. 0 gênero, portanto, não é algo que está dado, mas é construído social e culturalmente e envolve um conjunto de processos que vão marcando os corpos, a partir daquilo que se identifica ser masculino e/ou feminino. Se estamos cientes de que o gênero é a construção social do sexo, precisamos considerar que aquilo que no corpo indica ser masculino ou feminino não existe naturalmente. Pois construído assim e por esse motivo não é, desde sempre a mesma coisa (p. 75).

A instituição escolar tem um importante papel na construção dos elementos de gênero, e nesse aspecto algumas experiências do nosso cotidiano foram silenciadas ou apenas sussurradas (CRUZ, 2011). A psicóloga e doutora em educação Cruz (2011) estudou questões de gênero na escola e relata que a maioria dos sujeitos desse contexto tem um exemplo de situações acerca do tema: aquele aluno que queria brincar de bonecas, a menina que não "abria mão" de um boné, o adolescente que mudou sua maneira de andar, pintou as unhas e fez as sobrancelhas. Tais situações causam estranhamento e dificuldade na hora de agir, isso porque em nossa própria formação não tivemos discussões qualificadas sobre as relações de gênero e sexualidade - como se fossem temas pouco relacionados à vida escolar.

A partir disso, a sociedade criou estereótipos, que são, segundo Pereira (2012):

Sistemas de crenças socialmente compartilhadas a respeito de determinados entes, em geral membros de uma categoria social, que tem por referentes suposições sobre a homogeneidade grupal e sobre os padrões de comportamento comuns adotados pelos membros do grupo, cujos fundamentos são encontrados nas teorias implícitas a respeito dos fatores que determinam os padrões de conduta dos indivíduos avaliados mediante a aplicação de um julgamento categórico, usualmente, porém não exclusivamente, fundamentado em suposições sobre essências ou traços psicológicos, concebidos como intercambiáveis entre os membros do grupo ou categoria (p. 54).

Os seres humanos criaram vários discursos estereotipados e as próprias crianças são influenciadas por eles, como: cor de menina é rosa e cor de menino é azul; as diferenças entre brincadeiras de meninos e brincadeiras de meninas, em que muitos meninos não querem brincar de boneca porque é brincadeira de menina, por exemplo. Compreende-se, desse modo, que os estereótipos são generalizações que as pessoas fazem sobre comportamentos ou características de outros.

Segundo Pereira (2012), os estereótipos são pressupostos sobre determinadas pessoas, e muitas vezes eles acontecem sem que haja o conhecimento acerca dos grupos sociais ou das características dos indivíduos que são estereotipados, como: aparência, condições financeiras, comportamento e sexualidade. Tal situação reflete-se na tirinha abaixo (Figura 1). As crianças, em geral, pensam que somente a menina deve brincar de boneca e o menino de futebol, por exemplo. Então questionamos: por que menino não pode brincar de boneca? 
Figura 1: Brincando de Boneca.
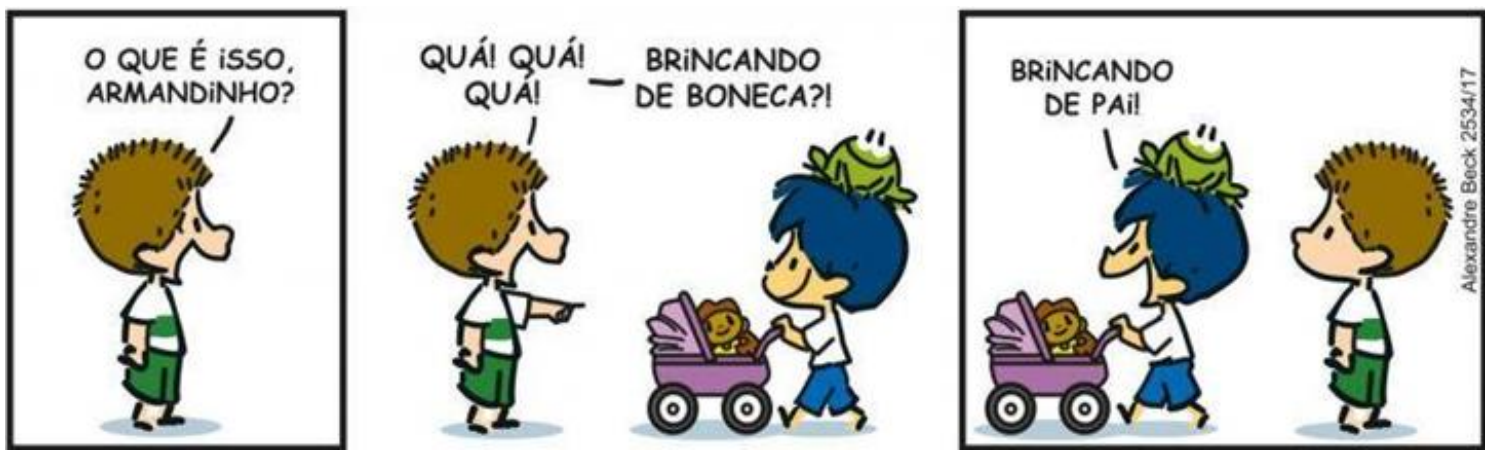

Fonte: Retirada do site https://tirasarmandinho.tumblr.com/.

Considerando o cenário apresentado na tira, acreditamos que, em momentos como esse, podemos interferir e criar uma problematização com os/as estudantes: só porque é rosa menino não pode usar? É preciso evidenciar que os meninos podem usar todas as cores e as meninas também. Questionamos sobre a Figura 1: Por que menino não pode brincar de boneca? Se, ao fazer isso, pode estar se preparando - se algum dia desejar - para ser um bom pai? Se menino não pode brincar de boneca, menina não pode jogar futebol? O que ganhamos com os estereótipos instituídos socialmente acerca da relação binária homem/mulher para a qualidade das relações culturais?

Figura 2: Carrinho é de menino e boneca é de menina.

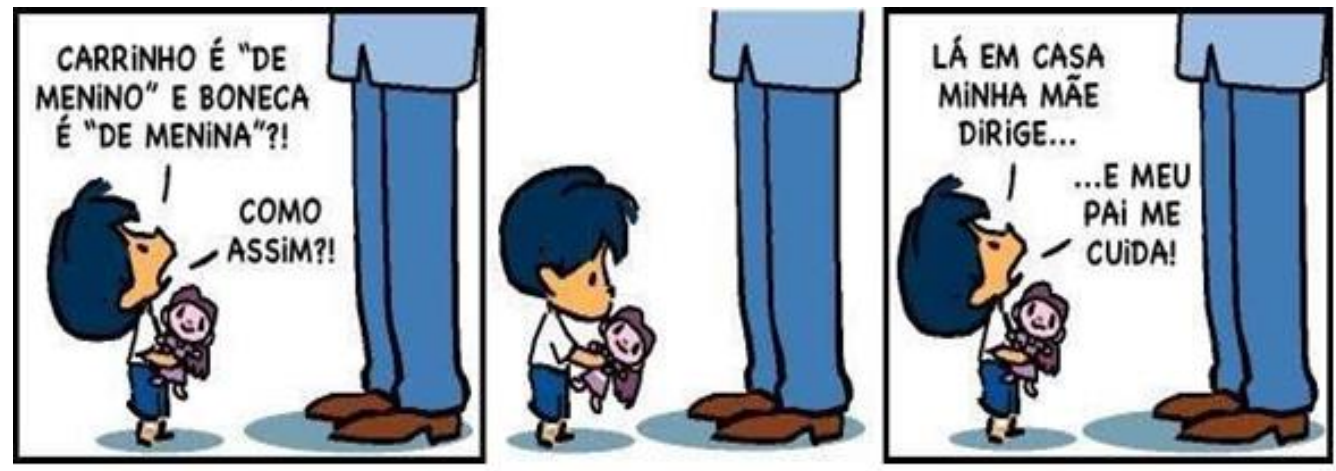

Fonte: Retirada do site https://tirasarmandinho.tumblr.com/.

Como exposto na Figura 2, não é apenas a mulher que deveria cuidar da criança em casa. O homem também tem o dever de cuidar do seu filho, assim como a mulher também tem direito de dirigir e fazer várias outras atividades equivalentes às dos homens. Os estereótipos podem ser perigosos porque acabam fomentando visões preconceituosas sobre aquele/a quem se fala. Nas palavras de Damasceno (2008),

Produzir estereótipos serve para manutenção tanto da ordem social quando da ordem simbólica de nossa sociedade. As dificuldades impostas pelo seu uso se refere ao seu caráter de reduzir, essencializar, naturalizar e fixar a diferença do Outro. Para tanto, estereótipo usa "cisão" como estratégia. Esse divide o normal e o aceitável do anormal e do inaceitável. Então exclui ou espelhe tudo aquilo que não se adapta, que é diferente (p. 3).

Ao ver filmes, novelas e propagandas aprendemos a sonhar, a desejar, a recusar. Com as crianças o processo é o mesmo, pois aprendem, por exemplo, que rosa é cor de menina e azul cor de menino vendo as persistentes propagandas de brinquedos. Assim, também aprendem que ser igual ao "gay" ou à "periguete" da novela é algo ruim. Quase sempre esses personagens são estereotipados, são tidos como "tipos" e não ser humanos complexos/completos, como, aliás, somos todos. 
Frazão e Rocha (2005) elucidam que "Quando as diferenças entre feminino e masculino são suprimidas, impedimos a constituição de uma identidade em consonância com a identidade de gênero, o que gera conflitos tanto intrapsíquicos quanto relacionais" (p. 28). 0 termo "gênero" não só é usado para representar a diferença social e psicológica entre homens e mulheres, como também para delinear a identidade do indivíduo. Por isso, essas questões não podem ser suprimidas e sim exprimidas. As questões de gênero e seus estereótipos desencadeiam atitudes de violências, o que ocorre também na escola.

Vianna e Unbehaum (2006) analisaram as políticas de Direitos Humanos sobre a definição do conceito "Identidade de gênero e orientação sexual", no intuito de salientar que essas temáticas devem ser acrescentadas no currículo escolar. O caminho percorrido pelas políticas públicas está em processo de desenvolvimento de uma política de igualdade. Os autores/as relatam que, por exemplo, nas etapas do Ensino Fundamental (anos iniciais e anos finais), a orientação sexual deve enfocar as dimensões sociológicas, psicológicas e fisiológicas da sexualidade.

O termo sexualidade ainda é considerado um tabu, por isso é difícil para a maioria dos/as professores/as abordarem esse tema. Destarte, encontramos aí a importância que possui este estudo, ao ser proposto em um curso de Formação Inicial de Professores: por estar nas políticas de Direitos Humanos se torna essencial. Ademais, destacamos que não é papel apenas do professor, mas também da família, sociedade, ou seja, é o papel de todos discutir sobre as relações de gênero.

\section{DISCUSSÃO E ANÁLISE DOS DADOS COLETADOS}

A partir da análise das respostas dos/as estudantes é que construímos as discussões a seguir. A Tabela 1 alude à concepção de gênero. Em cor vermelha de texto estão as análises das respostas que os/as estudantes modificaram ao final da pesquisa-ação, posto que após a explicação das temáticas os/as estudantes poderiam modificar as questões.

Tabela 1. Concepção de gênero.

\begin{tabular}{lcc}
\hline O que é gênero? & Estudantes & Total \\
\hline Identidade. & $\mathrm{E} 1, \mathrm{E} 3, \mathrm{E} 5, \mathrm{E}$ 8, E11, E16, E19, E21, E25, E18. & 10 \\
\hline Diferença de sexo. & $\mathrm{E} 2, \mathrm{E} 4, \mathrm{E} 6, \mathrm{E} 7, \mathrm{E} 12, \mathrm{E} 13, \mathrm{E} 14, \mathrm{E} 15, \mathrm{E} 19, \mathrm{E} 23, \mathrm{E} 24, \mathrm{E} 26, \mathrm{E} 27$. & 13 \\
\hline Orientação sexual. & $\mathrm{E} 5, \mathrm{E} 10$. & 02 \\
\hline Escolha/opção. & $\mathrm{E2}, \mathrm{E} 8, \mathrm{E} 21, \mathrm{E} 25$. & 04 \\
\hline Não soube responder. & $\mathrm{E} 9, \mathrm{E} 17, \mathrm{E} 20, \mathrm{E} 22$. & 04 \\
\hline Orientação sexual. & $\mathrm{E6}, \mathrm{E} 12, \mathrm{E} 13, \mathrm{E} 15, \mathrm{E} 17, \mathrm{E} 18, \mathrm{E} 19, \mathrm{E} 20, \mathrm{E23}, \mathrm{E} 27$. & 10 \\
\hline
\end{tabular}

Fonte: Dados da pesquisa (2019).

A maioria dos/as estudantes, 13, conceituou gênero, inicialmente, como a diferença entre o sexo masculino e feminino. Nove estudantes consideraram gênero como identidade, e cabe salientar, nesse contexto, que a essencialidade das identidades está sendo posta cada vez mais em xeque, o corpo 
acaba sendo uma referência tangível (WEEKS, 1995). Um/a estudante, após a intervenção, modificou sua concepção e respondeu que gênero diz respeito à identidade de uma pessoa.

Dois/duas estudantes compreendem o gênero como a orientação sexual ou a forma como cada indivíduo identifica-se, e, como relata Louro (1997), o termo é conhecido como aquilo que diferencia socialmente as pessoas. Quatro estudantes entendem que o gênero advém de uma escolha ou opção, o que é um pensamento equivocado, pois, segundo Goellner (2010), o gênero é uma construção social e cultural que difere o corpo feminino do masculino.

Quatro estudantes não souberam responder ao questionamento. Ao final das explicações, dez estudantes alteraram suas respostas, acrescentando que se trata da orientação sexual de cada pessoa. Tais posições envolvem vários aspectos, como os Parâmetros Curriculares Nacionais (PCN's) (BRASIL, 1997) apontam, como "fatores biológicos, culturais, sociais e de prazer" (p. 7).

Neste sentido, de modo a ampliar as compreensões, a Tabela 2 se refere às diferenças entre gênero e sexualidade. Uma resposta está em cor vermelha de texto, pois foi acrescentada por dois/duas estudantes.

Tabela 2. Diferenças entre gênero e de sexualidade.

\begin{tabular}{lcc}
\hline \multicolumn{1}{c}{$\begin{array}{c}\text { Existe diferença entre gênero e } \\
\text { sexualidade? Explique. }\end{array}$} & Estudantes & Total \\
\hline Sim. & $\begin{array}{c}\text { E1, E2, E3, E4, E5, E6, E7, E8, E10, E11, E13, } \\
\text { E14, E15, E18, E20, E22, E24, E25, E27. }\end{array}$ & 19 \\
\hline Não. & E19. & 01 \\
\hline $\begin{array}{l}\text { Não soube responder. } \\
\text { E2, E3, E5, E7, E8, E10, E12, E13, E16, E17, } \\
\text { E18, E21, E22, E23, E24, E26. }\end{array}$ & 16 \\
\hline $\begin{array}{l}\text { Gênero: Masculino e feminino. } \\
\text { Sexualidade: orientação sexual. }\end{array}$ & E4, E15, E27. \\
\hline $\begin{array}{l}\text { Gênero: Masculino e feminino. } \\
\text { Sexualidade: identidade. }\end{array}$ & E6. \\
\hline $\begin{array}{l}\text { Gênero; Identidade. Sexualidade: } \\
\text { Por quem se atrai. }\end{array}$ & E11, E14. \\
\hline $\begin{array}{l}\text { Gênero: Escolha. Sexualidade: } \\
\text { Expressões. }\end{array}$ & E25, E27. \\
\hline $\begin{array}{l}\text { Sexualidade é tudo que envolve o corpo } \\
\text { e prazeres. }\end{array}$ & E12, E15. \\
\hline
\end{tabular}

Fonte: Dados da pesquisa (2019).

A maioria dos/as estudantes, 19, admitem que há diferença entre gênero e sexualidade. Entretanto, 11 estudantes não souberam explicar a diferença entre os dois conceitos. Nas explicações, quatro estudantes responderam que gênero está relacionado à diferença entre masculino e feminino, e outros/as quatro estudantes salientaram que gênero se refere à identificação de cada pessoa.

Em relação à sexualidade, foram identificadas diferentes explicações nas respostas: três estudantes concluíram ser a orientação sexual, um/a estudante compreende que a sexualidade é a identidade e 
dois/duas relacionam sexualidade às expressões culturais. Ao final da intervenção, apenas dois/duas estudantes responderam que sexualidade está relacionada às expressões e sentimentos. Segundo Gurgel (2010), está ligada ao prazer.

Nas respostas da maioria dos/as estudantes há diferenças entre gênero e sexualidade, mas muitos/as não souberam explicar quais são as diferenças. As respostas variam entre identidade, orientação sexual, feminino e masculino. A partir disso, se confundem sobre esses aspectos, entendendo sexualidade como identidade ou orientação sexual.

Por ser uma categoria social, o gênero pode ser construído e desconstruído, ou seja, pode ser entendido como algo mutável e não limitado. Sendo assim, apesar de gênero e sexualidade serem conceitos diferentes, não deixam de ser interdependentes.

A Tabela 3 traz as concepções dos/as estudantes sobre os estereótipos de gênero, tendo duas respostas em vermelho.

Tabela 3. Estereótipo de gênero.

\section{Você sabe o que é estereótipo de gênero? Explique.}

Estudantes

E1, E2, E3, E4, E6, E7, E8, E9, E10, E11, E12, E13, $E 14, E 15, E 16, E 22, E 23, E 25, E 26, E 27$.

\begin{tabular}{ccc}
\hline Sim. & E5, E18, E19, E21 & 04 \\
\hline Feminicídio e masculinidade. & E5. & 01 \\
\hline Não soube responder. & E17, E19, E20, E21, E24. & 05 \\
\hline $\begin{array}{c}\text { Padrão: Coisas de menino e coisas } \\
\text { de menina. }\end{array}$ & E5, E6, E13, E14, E15, E20, E27. & 07 \\
\hline Rótulos que a sociedade impõe. & E18, E23, E25. & 03 \\
\hline & Fonte: Dados da pesquisa (2019).
\end{tabular}

Observamos, na Tabela 3, que quatro estudantes sabem o que são estereótipos de gênero (pois responderam "sim"), já 20 estudantes responderam que não sabem. Um/uma estudante escreveu sobre estereótipo de gênero como feminicídio e masculinidade, sendo que os estereótipos, muitas vezes, são os causadores dessas violências de gênero. De acordo com Pereira (2012), acontecem por não ter conhecimento sobre grupos sociais ou características de indivíduos, assim acabam fomentando visões preconceituosas.

Cinco estudantes não souberam explicar a definição de estereótipo. Nas palavras de Damasceno (2008), estereótipo é aquilo que não se adapta, que é diferente. Depois da explicação, três relatam que estereótipos são rótulos que a sociedade impõe e sete declaram como "padrões" como coisas de menino e coisas de menina (PEREIRA, 2011).

A Tabela 4 traz exemplos de estereótipos que os/as estudantes conhecem. 
Tabela 4. Exemplos de estereótipos.

\begin{tabular}{|c|c|c|}
\hline $\begin{array}{c}\text { Quais os estereótipos que } \\
\text { você conhece? }\end{array}$ & Estudantes & Total \\
\hline Não conhece & $\begin{array}{l}\text { E1, E2, E3, E4, E5, E6, E7, E8, E9, E10, E11, E12, E13, E14, } \\
\text { E15, E16, E18, E20, E21, E22, E23, E24, E25, E26, E27. }\end{array}$ & 25 \\
\hline Beleza, racial, econômica. & E17. & 01 \\
\hline $\begin{array}{l}\text { Certos comportamentos definem o } \\
\text { gênero. }\end{array}$ & E19. & 01 \\
\hline $\begin{array}{l}\text { Rosa é cor de menina e azul é cor } \\
\text { de menino. }\end{array}$ & E6, E13, E18, E20, E23. & 05 \\
\hline $\begin{array}{l}\text { Brincadeiras de menino e de } \\
\text { menina. }\end{array}$ & E15, E27. & 02 \\
\hline $\begin{array}{l}\text { A menina é dona de casa e o } \\
\text { menino trabalha fora de casa. }\end{array}$ & E18. & 01 \\
\hline
\end{tabular}

Fonte: Dados da pesquisa (2019).

De acordo com as respostas, apenas dois/duas estudantes souberam dar exemplos de estereótipos. Os/as demais, provavelmente, desconheciam o significado de estereótipo e por isso não apresentaram exemplos. Após os diálogos, oito estudantes entenderam que os estereótipos estão relacionados a padrões considerados "corretos", impostos pela sociedade (PEREIRA, 2011).

Considerando as análises das respostas, compreendemos que muitos alunos/as não sabiam o que é estereótipo de gênero, mas após as explicações aprenderam seu significado. Em relação aos estereótipos em geral, muitos responderam que não conheciam, mas após os diálogos tiveram suas dúvidas sanadas. Por isso é importante trabalhar a temática gênero na escola, pois ela está inserida nesse contexto de discussão (CRUZ, 2011).

Neste sentido, a próxima categoria relata acerca da importância das temáticas desenvolvidas na aula. A Tabela 5 tem o intuito de demonstrar as percepções dos/as estudantes sobre a importância do estudo destas temáticas. Por não haver respostas que foram alteradas após a intervenção, não há o destaque em vermelho.

Tabela 5. Importância do estudo das temáticas abordadas.

\begin{tabular}{|c|c|c|}
\hline $\begin{array}{l}\text { Você acredita que essas temáticas } \\
\text { "corpo, gênero e sexualidade" são } \\
\text { importantes para serem discutidas } \\
\text { na sua escola de formação? Por quê? }\end{array}$ & Estudantes & Total \\
\hline Sim. & $\begin{array}{c}\text { E1, E2, E3, E4, E5, E6, E7, E8, E9, E10, E11, } \\
\text { E12, E13, E14, E15, E16, E18, E19, E20, E21, } \\
\text { E22, E23, E24, E25, E26, E27. }\end{array}$ & 26 \\
\hline É importante falar sobre o corpo humano. & $\mathrm{E} 1, \mathrm{E} 14, \mathrm{E} 21, \mathrm{E} 25, \mathrm{E} 26$. & 05 \\
\hline Muitas vezes não temos essas informações. & E2, E6, E12, E13, E15, E18, E22, E24, E27. & 09 \\
\hline $\begin{array}{l}\text { Temos que ter esse conhecimento para sabermos } \\
\text { explicar em sala de aula. }\end{array}$ & E4, E5, E9, E16, E20, E23. & 06 \\
\hline Para ter respeito ao próximo. & E5, E11. & 02 \\
\hline Para esclarecer dúvidas. & E7. & 01 \\
\hline Porque são assuntos presentes no cotidiano. & E19. & 01 \\
\hline Não soube responder. & E17. & 01 \\
\hline
\end{tabular}

Fonte: Dados da pesquisa (2019). 
Percebemos que a maioria dos estudantes, 26, responderam que "sim", que é importante trabalhar a temática nas aulas, nenhum/a estudante respondeu "não". Sendo que cinco estudantes responderam ser importante falar sobre o corpo humano, pois muitas vezes não têm essas informações e precisam ter esse conhecimento para saber explicar em aula (CRUZ, 2011).

Segundo Vygotsky (1978), as crianças são seres histórico-culturais e são influenciadas pelo seu meio, por isso a importância de trabalhar essas temáticas em sala de aula, como dois/as estudantes destacaram: para ter respeito ao próximo. Um/a estudante declarou que o preconceito acerca das relações de gênero é um assunto presente no cotidiano, e que causa muitos estereótipos e violência, por isso precisam ser abordados em sala de aula (CRUZ, 2011).

A Tabela 6 apresenta os dados sobre a participação em palestras, grupos de estudo e oficinas pelos/as estudantes. Essa resposta também não foi modificada por nenhum dos/as estudantes após a intervenção.

Tabela 6. Participação dos estudantes em formações relacionadas ao tema

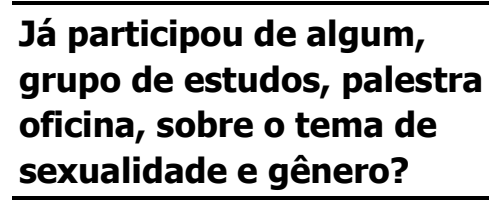

\begin{tabular}{lcc}
\hline Sim. & E5, E6, E13, E22, E25, E26, E27. & 07 \\
\hline Não. & E1, E2, E4, E7, E8, E9, E10, E12, E14, E16, E18, & 16 \\
& E19, E20, E21, E23, E24. & \\
\hline
\end{tabular}

\begin{tabular}{lll}
\hline Não lembra. & E3, E15. & 02 \\
\hline Sim, no Youtube. & E11. & 01 \\
\hline Não soube responder. & E17. & 01 \\
\hline
\end{tabular}

Fonte: Dados da pesquisa (2019).

A maioria dos/as estudantes não havia participado de nenhuma atividade sobre a temática anteriormente, pois apenas sete estudantes responderam que "sim", enquanto 16 estudantes responderam que "não". Identificamos que um/a estudante descreve que procurou compreender o assunto por meio do Youtube. $\mathrm{O}$ fato de um/a estudante precisar pesquisar em sites online sobre 0 assunto, é, no mínimo, preocupante. A escola deve ser um lugar no qual o aluno se sente seguro para perguntar, falar e refletir, e o diálogo sobre gênero e sexualidade é de extrema importância para que isso aconteça (RIBEIRO, 1999). Quando o/a estudante não se sente seguro na escola, nem no ambiente familiar, procura outros meios de saber, o que o afasta da afetividade e diálogo que pode obter com o seu meio social.

A partir deste estudo, foi possível perceber que os/as estudantes ressignificaram os conceitos que possuíam. Assim, partindo dos conteúdos estudados, entendemos a importância do diálogo aberto em aula, por meio do qual os/as estudantes puderam/podem se expressar, tirar dúvidas, falar abertamente e refletir sobre essas e outras temáticas.

\section{CONCLUSÃO}

Em virtude da análise apresentada nesta investigação, partimos do pressuposto inicial de que não existe conhecimento, por parte dos/as estudantes, futuros/as professores/as, para lidar com as temáticas de gênero e sexualidade. Percebemos que os/as estudantes do Curso Normal de Nível 
Médio apresentam discursos estereotipados socialmente ou mesmo fragmentados, além de não relacionar as temáticas em estudo. Porém, ao analisar as respostas obtidas com o questionário, foi possível perceber que alguns/algumas estudantes, durante ou após a aula com as explicações, diálogos e reflexões, modificaram suas respostas e desenvolveram uma visão mais integrada acerca das relações de gênero e sexualidade. Interpretação essa que foi além do nível biológico, posto que envolveu os aspectos cultural, psicológico, social e histórico.

Considerando esses aspectos, na intervenção e nas respostas ao questionário, notamos que realmente existe desconhecimento dos/as estudantes sobre as temáticas abordadas. Identificamos, na questão da participação em formações sobre a temática, que os/as estudantes perceberam o quanto é importante ter esse conhecimento para futuramente trabalhar com seus/suas futuros/as alunos/as. Após esta intervenção, pode-se compreender que as aulas de Ciências ou de Biologia e a relação com essas temáticas nos desenvolvem como futuros/as professores/as, no intuito de reconhecer que gênero é uma temática indissociável, pois, na escola e na sala de aula, por serem locais de interações, ocorrem muitas situações sobre os temas aqui discutidos e muitas vezes, os/as professores/as não sabem como lidar com elas. Por serem assuntos de cunho polêmico, alguns acabam não os desenvolvendo com os/as estudantes.

Diante disso, é importante dialogar com os/as estudantes sobre assuntos que ainda hoje são considerados tabus, uma vez que a escola tem o papel de formar um ser humano crítico e reflexivo, formado para atuar com cidadania. A escola pode contribuir para o entendimento das relações de gênero ao problematizar temas como a violência contra a mulher, por exemplo, dispondo de ambientes e profissionais que possibilitem uma prática de valores, igualdade e respeito às diferenças. Um exemplo de combate aos estereótipos de gênero é deixar as crianças brincarem juntas, seja de carrinho, seja de boneca.

Além disso, destacamos que o papel de ensinar o respeito perante às diferenças não é somente papel do/a professor/a, mas sim de todos, por isso está nas políticas de Direitos Humanos. E, para isso, a escola precisa do auxílio da família e da sociedade para elaborar esse trabalho, que deve ocorrer em conjunto. Auxiliar a criança é uma das funções docentes e fazer isso com zelo, respeito e criticidade é o melhor caminho.

\section{REFERÊNCIAS}

ALARCÃO, Isabel. Professores reflexivos em uma escola reflexiva. 7. ed. São Paulo: Cortez, 2010.

BUGALSKI, Osmar. URBAN, Ana Claudia. O aluno como sujeito da sua própria aprendizagem. Disponível em: http://www.diaadiaeducacao.pr.gov.br/portals/cadernospde/pdebusca/producoes_pde/2016/2016_ pdp_hist_ufpr_osmarbugalski.pdf. Acesso em: 16 mar. 2021.

BRASIL. Lei de Diretrizes e Bases da Educação Nacional. Lei no 9.394/96, 20 de dezembro de 1996.

BRASIL. Parâmetros Curriculares Nacionais (1 a a $5^{\mathbf{a}}$ ano): orientação Sexual. Secretaria de Educação Fundamental, Brasília, MEC/SEF, 1997. 
COLLING, Ana Maria.; TEDESCHI, Losandro Antonio. Dicionário crítico de gênero. Dourados: Ed. Universidade Federal da Grande Dourados, 2019.

CRUZ, Elizabete Franco. Banheiros, travestis, relações de gênero e diferenças no cotidiano da escola. Revista Psicologia Política. São Paulo, v. 11, n. 21, p. 73-90, jun. 2011.

DAMASCENO, Janaína. O corpo do outro: construções raciais e imagens de controle do corpo feminino negro: o caso da Vênus hotentote. In: Seminário Internacional Fazendo Gênero, 8, 2008, Florianópolis. Anais... Florianópolis: UFSC, 2008. Disponível em: http://www.fazendogenero.ufsc.br/8/sts/ST69/Janaina_Damasceno_69.pdf. Acesso em: 02 nov. 2020.

FRANCO, Maria Amélia. Pedagogia da pesquisa-ação. Educação e Pesquisa. São Paulo, v. 31, n. 3, p. 483-502, set./dez. 2005.

FRAZÃO, Lilian Meyer; ROCHA, Sérgio Lizias. Gestalt e gênero: configurações do masculino e feminino na contemporaneidade. São Paulo: Livro Pleno. 2005.

GOELLNER, Silvana Vilodre. A educação dos corpos, dos gêneros e das sexualidades e o reconhecimento da diversidade. Cadernos de Formação RBCE, Porto Alegre, março de 2010.

LOURO, Guacira Lopes. Nas redes do conceito de gênero. In: LOPES, Marta Júlia. (Org.). Gênero e saúde. Porto Alegre: Artes Médicas, 1997.

LÜDKE, Menga; ANDRÉ, Marli. Pesquisa em educação: abordagens qualitativas. São Paulo: EPU, 1986.

MACEDO, Elizabeth. Esse corpo das Ciências é meu? In: SELLES, Sandra Elizabeth.; FERREIRA, Márcia;(org.). Ensino de Biologia: conhecimentos e valores em disputa. Niterói: Eduff, 2005.

PEREIRA, Marcos Emanoel; MODESTO, João Gabriel; MATOS, Marta Dantas. Em direção a uma nova definição de estereotipos: teste empírico do modelo num primeiro cenário experimental. Psicologia e Saber Social, Rio de Janeiro, v. 1, n. 2, p. 201-220, dez. 2012.

RIBEIRO, Vera Masagão. A formação de educadores e a constituição da educação de jovens e adultos como campo pedagógico. Educação \& Sociedade, Campinas, v. 20, n. 68, p. 184-201, dez., 1999.

ROGERS, Carl. Tornar-se pessoa. 5. ed. São Paulo: Martins, 2001.

VIANNA, Claudia; UNBEHAUM, Sandra. Gênero na Educação Básica: quem se importa? Uma Análise de documentos de Políticas Públicas no Brasil. Educação \& Sociedade, Campinas, v. 27, n. 95, p. 407-428, maio/ago. 2006.

VYGOTSKY, Lev Semyonovich. Interaction between learning and development. Readings on the development of children. Cambridge, MA: Harvard University Press. v. 23, n. 3, p. 34-41, 1978.

VYGOTSKY, Lev Semyonovich. Pensamento e linguagem. 2. ed. São Paulo: Martins Fontes, 2003. WEEKS, Jeffrei. Invented moralities: sexual values in an age of uncertainty. Nova York: Columbia University Press, 1995. 